\title{
What is fashion law?
}

Before we get into the legal issues, it is worth reminding ourselves how large and important the fashion industry is for the global and, in particular, the European economy. Some of this will be very familiar for readers. If so, feel free to skip ahead to the later part of the chapter which gives an overview of some of the more current fashion law trends around intellectual property, franchising, ethical fashion, e-commerce and fashion technology.

\subsection{The economics of fashion}

The global fashion market is valued at US\$3,00o billion (or 2 per cent of global GDP). Womenswear is the most valuable segment at US $\$ 621$ billion but the men are catching up; menswear is currently worth around US\$402 billion. ${ }^{1}$ Europe is a significant contributor to this total. Indeed, five million people in the EU are directly employed in the fashion value chain and over one million people are employed in the high-end fashion and retail industries. ${ }^{2}$

Europe is particularly well known for its design houses. Three out of the four major global fashion weeks (London, Paris and Milan) take place in Europe. It is also an important centre for manufacturing, particularly countries in Southern and Eastern Europe such as Portugal, Spain, Italy, Romania and Turkey. Italy alone accounts for around 50 per cent of total EU footwear production with Portugal and Spain bringing the combined percentage close to 70 per cent.

Very broadly speaking, Europe tends to manufacture higher quality and more niche items e.g., sports protection clothing and footwear. Its

1 Data courtesy of Fashion United https://fashionunited.com/global-fashion-industry-statistics.
2 https://ec.europa.eu/growth/sectors/fashion/high-end-industries/eu_en. 
main export markets are Russia and the US with increasing growth to China and the Middle East, particularly the United Arab Emirates.

Because of fashion's importance to the European economy, the EU has been at the forefront of legislating to ensure that features such as labelling of fibre names and origin of goods is clear and consumers are adequately protected from poor quality or potentially dangerous goods. Further, as technology starts to dominate all traditional industries, Europe has embraced fashion technology, particularly around smart textiles and other forms of wearable technology.

Europe's main suppliers are China (almost 50 per cent of all imports), and Vietnam but other countries such as Pakistan, Bangladesh and Sri Lanka are also very important and offer tax reliefs which make them particularly popular for the manufacture of lower value items.

\subsection{Intellectual property}

Although this book is focused on European fashion, most countries worldwide are connected to the fashion industry and consequently a segmented approach to fashion in a global economy is only helpful at a high level. Intellectual property rights are one of the most harmonised sets of laws worldwide, they provide fairly consistent protection over trade origin, creative works, inventions and, to a less consistent extent, product design.

Without intellectual property rights it would be virtually impossible for the European fashion industry to continue. These rights enable a business to compete knowing that it has a legal monopoly which protects the time and money it has invested into the brand. Although the European fashion industry by no means avoids counterfeits and close copies of their products, intellectual property rights enable businesses to protect their products and enforce these rights in all relevant territories worldwide. The success of enforcement varies based on strategy and budget.

While intellectual property can be a sword, most fashion businesses, at one time or another, find themselves both wielding the weapon and having it pointed at them. It is all too easy for designers to take inspiration a bit too literally and the line between following fashion trends 
and outright copying can be a very fine one. This can be damaging in terms of legal costs, financial compensation, internal investigation and, most importantly, reputation. The public can usually forgive a one-off instance but a pattern of infringement is much less forgivable and can substantially erode public trust.

The different types of intellectual property are discussed in Part II, they include trade marks (Chapter 3); copyright (Chapter 4); image rights (Chapter 5); designs (Chapter 6); and passing off, domain names, confidential information (Chapter 7 ). The methods of using these rights are discussed in an enforcement context (Chapter 20) and more specifically in relation to counterfeit goods (Chapter 24).

\subsection{Franchising, licensing, distributors and agents}

There are a few tried and tested methods for growing your business by working in collaboration with other businesses. Franchising, licensing, distribution or agency relationships can be used to help break into new markets or diversify into new products. For example, it is common for fashion brands to diversify from clothing and footwear into products such as perfumes, sunglasses and cosmetics which have different methods of manufacture and routes to market.

Each of these options relies on a solid contract which is easy to understand and enforce. There are two fundamental keys to making these arrangements a success. The first is taking the time to meet, learn and understand whether the proposed partner is truly the right fit for your business. The second is putting the right contracts in place to protect you if anything goes wrong in the future.

Broadly speaking franchising means licensing your brand and business to a third party who builds its own version of your business in a particular market but ultimately is accountable to you. It can offer entrepreneurial individuals the opportunity to start and run what is effectively their own business without having to spend the time developing their own brand. It offers the brand the opportunity to grow into new markets very quickly. Franchising is most commonly associated with bricks and mortar stores but it is becoming easier in the online environment and may be an attractive option if, for example, there are a lot of orders in a particular geographic region but fast fulfilment is a challenge. 
The main risk of franchising is that the actions of a bad franchisee can damage a brand irreparably. Consumers do not care who the legal owner is or what contractual arrangements are going on behind the scenes. If someone behaves badly under your brand, you are ultimately going to be held accountable, if not in the eyes of the law then definitely in the eyes of social media. Consequently, quality control and regular audits are essential.

Distributors help you to break into new markets. Exclusive distribution agreements can offer comfort to distributors who are investing in your brand while at the same time enabling quick and comprehensive entry into new markets. The distribution agreement can be segmented by product and geographic area. For example, it could cover sunglasses in an entire region (Scandinavia), a European country (Sweden) or city (Stockholm). Distribution agreements can come in various forms. In some cases, they give the right to both manufacture and sell a specific product in a particular territory for a fixed period of time. More commonly, it gives an exclusive ability to sell products which you have manufactured in a territory for a fixed period of time. It is important that issues such as marketing spend and quality control are carefully set out in the agreement.

You also need to bear in mind the risks of competition law (known as anti-trust law in the US). 'Exclusivity' and 'anti-competitive behaviour' share a very porous border; you do not want to be on the wrong side. If you have a large market share (either because the market is new or you work for a very large business), you should be particularly careful and make sure you obtain legal advice on the competition law risks associated with new business strategies.

Commercial agents are an alternative (or supplemental) means of scaling a fashion business. Agents are highly regulated by EU law and not only have a dedicated Directive but also come with their own body of case law. The EU rules which govern agency agreements are particularly onerous in terms of the calculation of commission (i.e., the agent's fee) and termination of an agency relationship.

An agent is essentially an individual or business which is authorised to act on behalf of another individual or business (often referred to as the 'principal'). They are most famous in the world of celebrity but are important to all industries, including fashion. If you have authorised an agent, they can enter into contracts which bind your business, 
potentially without your knowledge. An implicit authorisation is sufficient for the agency relationship to arise. An agency relationship can be created without a physical contract simply on the basis of 'a course of dealing'. In other words if you treat someone as though they are an agent, even if you do not call them one, they can be treated as an agent in the eyes of the law.

This all means that an agent can be in a very powerful position. If you delegate them too much authority, they can potentially run many aspects of your business without your knowledge or permission. There are limits, for example, agents are only allowed to work with potentially conflicting clients, such as rival fashion businesses, following full disclosure and consent. Nevertheless, there are obvious risks of confidential information and know-how being inadvertently misused. The different options for agents and distributors are discussed in Chapter 11 and franchising is covered in Chapter 18.

\subsection{Ethical fashion}

It is no great secret that fashion leaves a large environmental and societal footprint. Some disasters such as the collapse of the Rana Plaza factory in Bangladesh garnered massive international outrage; others such as the constant pollution of water following the use of harsh dyes and bleaches currently receive far less attention.

If you are manufacturing fashion items you have a responsibility to ensure that, among many other things, the raw materials, where possible, come from sustainable sources, and the workers are treated well, given sufficient pay, breaks, paid leave and are not placed in environmental conditions which could lead to long-term health damage.

The laws around employees in Europe are discussed in Chapter 10. Ethical fashion is discussed in more detail in Chapter 25, particularly in the context of the supply chain.

\subsection{The Internet}

Fashion is not unique in having faced major disruption from the Internet. Fashion purchases are increasingly made via social media and 
from mobile phones (although the phrase $\mathrm{m}$-commerce ${ }^{3}$ never really caught on). E-commerce is expected to represent over 16 per cent of global retail sales by 2021. ${ }^{4}$ Europe currently leads the way and is a major market for online sales.

There are all sorts of business models from the 'try now, pay later' whereby lots of products are curated and sent to potential purchasers to 'click \& collect' where you can pick up and return goods from all sorts of convenient locations. The latter approach has worked particularly well in the UK for John Lewis which is able to use its Waitrose food network for this purpose. Amazon has even introduced a service whereby delivery drivers are able to open your front door when they scan a package. Another approach which deals with many of the issues associated with sustainable fashion is typified by Rent the Runway ${ }^{5}$ (whose tagline 'buy less stuff' sums up the attitude of many so-called millennials). This business model allows you to rent high-end items on a short-term basis so you pay a fraction of the cost for an item which has a limited shelf life. There is a subscription option for regular users. Unsurprisingly, this is particularly popular for weddings and other similar events.

Although e-commerce involves significant savings in retail space and employees, it is not a complete licence to print money. In the EU, e-commerce is tightly regulated and returns of undesirable or faulty goods can be a very expensive process. Whether as a result or in spite of this tight regulatory framework, the EU has one of the most successful ecosystems for online retail in the world. The EU's consumerfocused legislation includes a two-week cooling off period following delivery. The consumer can notify the seller at any point in this twoweek period that they wish to return a product. This is followed by a further two-week period in which they can arrange for the product to be returned. In other words, you may sell an item online, deliver it and find it returned in a month, following which you are obliged to reimburse the purchase price and delivery costs.

The Internet offers vast opportunities and international reach but it is incredibly important that all countries where your products are offered for sale are carefully vetted and that you comply with local laws. For

\footnotetext{
3 Short for 'mobile commerce.'

4 Source: Worldwide Retail and Ecommerce Sales: eMarketer's Estimates for 2016-2021, 18 July 2017.

5 https://www.renttherunway.com/. One of the UK equivalents is http://hirethecatwalk.com/.
} 
example, it is very common for companies to receive letters claiming trade mark infringement from German and Swiss companies. Even if you have only sold a few products into Germany, ${ }^{6}$ you may be forced to rename all of those products worldwide on the basis that the goods are available online and can theoretically be shipped to Germany. Many of these trade marks are not in use but if they are less than five years old, they cannot be easily challenged and it is often more cost effective to simply rename with an agreed sell through period.

E-commerce channels are becoming more restrictive as the European market gets more sophisticated. For example, if you are an authorised seller of luxury goods, care will have to be taken as to how and where you sell those goods online. As you will see in Chapter 11, it is now legitimate for luxury fashion businesses to prevent their distributors from selling on sites such as Amazon on the basis that sale on mainstream e-commerce sites risks damaging their 'allure.' A more detailed overview of the issues relating to e-commerce is in Chapter 17.

Another issue which can affect the producers of niche fashion products, for example luxury items made from unusual animal skins or semi-precious stones, concerns the manner in which these goods can be imported. This is a particular problem for online retail if the goods are stored outside the European Economic Area (EEA). If the UK leaves the EU Customs Union, this issue will present quite a headache for many luxury brands who will need to think carefully about the timings for shipments if they are to avoid a hold up at Customs. The issues associated with Customs are considered in the context of taxation and logistics in Chapter 22.

\subsection{Counterfeit and parallel goods}

Another important aspect of brand image concerns parallel ${ }^{7}$ and counterfeit goods. It is good practice to monitor the sale of counterfeit products online, especially when they are carried out via third party sites such as eBay or via social media platforms. Even where the

6 Indeed, it is not unusual for the only time your product was actually purchased in Germany to be the time your opponent's German lawyer purchased it - under German law this seems to be sufficient to threaten legal proceedings.

7 Sometimes called grey goods. These are goods which are put on to the market elsewhere in the world but imported into a jurisdiction without your permission. In some limited circumstances it is possible to stop this resale. 
laws are consistent, the application of those laws can vary substantially across the EU.

In France, the courts are particularly protective of rights owners, as a recent criminal case ${ }^{8}$ concerning the sale of counterfeit copies of Adobe software on eBay demonstrates. A 'Mr X' sold almost 300 copies of the proprietary software without Adobe's consent. The French court also noted that $\mathrm{Mr} \mathrm{X}$ was carrying out a commercial activity, albeit an illegal one, but had failed to register it at the French Companies House. $\mathrm{Mr} \mathrm{X}$ was given a prison sentence and ordered to pay a fine of more than $€ 600,000$.

The UK's Supreme Court ${ }^{9}$ recently went one step further and confirmed that importers of genuine goods which were brought into the EEA, specifically the UK, without the rights holder's consent (in other words, parallel imports or grey goods) could be engaging in criminal activity. Consequently, they could face both a prison sentence and a fine which could result in their assets being seized as proceeds of crime.

Many forms of intellectual property infringement can form the basis of criminal proceedings. The enforcement of intellectual property rights is discussed in Chapter 20 and counterfeit goods are considered in Chapter 24.

\subsection{The rise of fashion technology}

Technology is converging with all existing industries in new, exciting and occasionally disturbing ways. The fashion industry is no different. Fashion technology is part of the broader trend toward wearable technology. This includes the Fitbit, Apple Watch and jewellery which taps you when someone important gets in touch. ${ }^{10}$ The most common fashion/tech overlaps tend to relate to fitness, social tracking and mood. ${ }^{11}$ For example, GPS chips can be integrated into all sorts of products

\footnotetext{
8 See the decision of the TGI de Limoges, jugement correctionnel of 11 th July 2017 (Adobe Systems Inc.c/ M. X.)

9 RvM (appellant) [2017] UKSC 58 https://www.supremecourt.uk/cases/uksc-2017-0oo6.html.

10 The current market leader in this area is probably Bellabeat https://webshop.bellabeat.com/.

11 For example, Sensoree makes various bioresponsive fashion items which provide aural, visual and tactile feedback dependent upon the wearer's emotions or mood: http://sensoree.com/.
} 
from umbrellas ${ }^{12}$ and suitcases ${ }^{13}$ to bracelets and rings. ${ }^{14}$ They could simply be used to tell you where your product is if it is lost or be triggered in a potentially dangerous situation. ${ }^{15}$

Fashion technology's move toward textile integration is particularly exciting. For example, fabrics which light up in the dark could save pedestrians and cyclists from injury on the roads. This is particularly beneficial in parts of the world, such as Europe, where the car is not necessarily the dominant means of transport.

One of the big issues with fashion tech is its sustainability and recyclability. ${ }^{16}$ It is hard enough to persuade people to recycle a woolly jumper but if it is embedded with LEDs it may not be possible to recycle at all. The EU has a strict regulatory regime around electrical items. For example, the WEEE Directive, ${ }^{17}$ set recycling and recovery targets for all types of electrical goods originally based on kilograms per head of population per annum recovered for recycling and now based on weight of electrical and electronic $(\mathrm{E} \& \mathrm{E})$ products entering the market. Similarly, the RoHS Directive ${ }^{18}$ sets restrictions upon EU manufacturers as to the material content of new electronic equipment placed on the market. ${ }^{19}$ Both of these Directives have been criticised for failing to have an adequate enforcement mechanism and, in the case of RoHS, for penalising EU manufacturers.

\footnotetext{
12 See, e.g., Kisha: https://www.getkisha.com/.

13 My favourite example of this is the G-RO - it is not the most attractive suitcase but the design is certainly innovative: https://uk.g-ro.com/. For a more stylish alternative see: https://www. rebeccaminkoff.com/products/so-connected-luggage-22-lgoo1mblk-matte-black.

14 Teen Vogue has assembled some great examples of how wearable fashion is becoming mainstream: https://www.teenvogue.com/gallery/wearable-tech-accessories.

15 See, e.g., Nimb: https://nimb.com/.

16 Some businesses have thought this through but it is not the norm. For example, CuteCircuit's LED dresses can be washed in a regular washing machine and customers can return the dress for recycling when it reaches the end of its life: https://shop.cutecircuit.com/collections/womenswear/ products/k-dress- 1 .

17 The Waste Electrical and Electronic Equipment Directive (WEEE) 2012/19/EU. The overall aim of WEEE was for the EU to recycle at least 2 per cent of electrical and electronics waste equipment by 2016.

18 The Restriction of Hazardous Substances Directive 2002/95/EC and updated in the RoHS 2 Directive 2011/65/EU.

19 Most famously, RoHS restricts the use of lead but it also covers nine other substances such as mercury and cadmium.
} 
The other big trend to hit fashion is the move toward customisation. ${ }^{20}$ This is facilitated by computer modelling and $3 \mathrm{D}$ printing. For example, it is possible to get a range of clothing items which match part of your unique genome or trousers which are engineered to perfectly fit you. This is important in the sporting world where tiny improvements can make the difference between first and second place. Trainer technology is leading the mainstream athleisure pack with companies such as Adidas making shoes from algae ${ }^{21}$ and Nike manufacturing ${ }_{3} \mathrm{D}$ printed recycled shoes.

As we have adapted to e-commerce, bricks and mortar stores have continued to suffer. However, physical stores are still important in terms of showcasing products and allowing them to stand out from the mainstream. The issues associated with commercial real estate are considered in Chapter 15, including the trend towards temporary locations and pop up stores. The connection to bricks and mortar stores may be revived again through augmented reality, smart mirrors, connected changing rooms ${ }^{22}$ and self checkouts. ${ }^{23}$ In the nearer future, augmented reality (AR) is likely to add a second dimension to bricks and mortar stores and may offer the opportunity to have the online experience (reviews, information and the best price) in store. ${ }^{24}$ AR glasses are slowly moving from the ultra naff Google glass to a high fashion alternative. With the indispensable help of the fashion industry, it is likely that AR will become commonplace in the very near future. Virtual reality (VR) raises some exciting opportunities. Although market penetration of VR headsets remains low, this is an exciting possibility for the future.

Finally, blockchain or 'distributed ledger' technology is an exciting new way of ensuring that the data related to wearable devices, the sustainability journey and ownership of intellectual property rights remains accurate and secure. You can read more about the potential

20 A good example of this is London based Unmade: https://www.unmade.com/.

21 Arielle Pardes, Slip Into Earth-friendly Running Shoes Made of Algae, Wired 29 June 2017 https:// www.wired.com/story/slip-into-earth-friendly-running-shoes-made-of-algae/.

22 Not as disturbing as it sounds. This essentially involves having a connected device in a changing room from which you can order a different size or browse a lookbook.

23 For example Amazon Go. Rebecca Minkoff has experimented with the use of this and related technology for luxury fashion, you can read the Engadget review here: https://www.engadget. com/2016/12/25/rebecca-minkoff-tech-stores.

24. Major retailers such as Zara have launched augmented reality apps. 
applications of blockchain technology to the supply chain in Chapter $25 .{ }^{25}$

\subsection{Selling your business}

For many people, the ultimate prize for all their hard work on a fashion business is the sale of their business (or in corporate jargon 'exit'). What form this exit takes is very fluid and there are lots of different and related opportunities. This might mean the sale of a particular brand, a division or product line or the entire business. It could mean the sale of the business to a competitor or via a listing on a public stock exchange. Lots of factors come into play when selling a business and the more you have followed the guidance set out in this book, the easier the sale process will be. Common issues arise around important contracts, key personnel and intellectual property rights. If these cannot be easily sorted out it may affect the amount of money that your business is sold for or even if it can be sold at all.

Given that a business has a very personal relationship for the founders, it can be hard to cease all involvement and you should think carefully about whether this is something you actually want. In addition to your paycheck, you should think about the loyal employees who enabled you to build up the business. How do you plan to reward them, and keep them motivated both before and after your exit?

\subsection{So, what's next?}

This first chapter gives you a flavour of what you can expect from the book itself but my hope is that the book is the beginning of a bigger conversation. The final chapter of the book looks toward the future and considers the major changes on the European fashion law horizon. These issues include Brexit, ${ }^{26}$ the rise and importance of data and the impact of fashion technology.

Many issues could not be covered in the book due to space limitations but that does not mean that issues such as insolvency and restructur-

\footnotetext{
25 And also in Rosie Burbidge, 'The Blockchain is in Fashion', 107(6) The Trademark Reporter $1262-7$.

26 'Brexit' has become shorthand for the UK's departure from the EU.
} 
ing are not important to the fashion industry. Similarly, the case law in Europe is constantly evolving and it is important to keep on top of legal developments to avoid any nasty surprises. Fortunately for you, not only is there the associated website, www.europeanfashionlaw. com, but there is the possibility of covering these issues in future editions.

If this book can help raise awareness of legal issues and help you to avoid expensive or reputational mistakes then it will have served its purpose. While books are not famed for their interactive nature, the website can help bridge this gap. Any issues which you would like covered in more detail or European countries whose legal systems you think deserve more attention can be considered in more detail on there - just let me know. Please do get in touch with your feedback as well as any insights you can share into the fashion law issues you and your business have faced.

\subsection{Instructing a lawyer}

Finally, while this book will give you some general guidance on the legal issues you are likely to face, it is no substitute for legal advice. The key to getting good quality, cost effective and timely legal advice is as follows:

1. Don't delay - Most legal problems become a lot more expensive if they are not dealt with up front. In some cases delay will mean that you lose a legal option altogether. It could, for example, result in the negotiation of an expensive commercial deal just so you can use your brand name in a particular territory.

2. Build a relationship - Go to legal events and get to know the lawyers and paralegals who are helping you on a day-to-day basis. The more you can share with them about what you are doing and your plans for the future, the better positioned they are to put the optimum strategy in place for you.

3. Negotiate a good deal for you - The main payment models for legal services are hourly rate, fixed fee or retainer. For some people a retainer model can work well, it gives the comfort of known legal spend and the flexibility to cover a range of issues. Fixed fees provide certainty but the scope of the fee must be clear up front. They 
can be harder to agree for less predictable legal issues such as litigation where the full story does not tend to be known at the outset. Although people have long been predicting the death of the hourly rate, this remains the dominant method of billing for most law firms.

4. Less is more - If you want to avoid a nasty surprise at the end of the month, be efficient in the methods of communication with your legal team. A single clear and concise email with all relevant documents attached will take you longer to prepare but will ultimately yield better results than sending over a series of emails or unlabelled documents with little explanation. This approach gives you time to think through the issues and avoids incurring additional expense by following up with comments which can fundamentally change the legal strategy once your lawyer has started work (and fees have been incurred). It is often useful to follow up this initial email with a call to discuss the details. This call can be used to ensure that your lawyer has all relevant information and you are aware of the risks of adopting your particular strategy.

5. Read and comment on the drafts - You are the expert on any factual information included in any legal communication with an opponent, your landlord, the court or similar. It is therefore important that you read through all the draft legal documentation you are sent carefully and make sure it is complete and accurate before it is sent or filed. Again, it is more efficient, and consequently will save you money, if you send a single set of comments either by reference to the paragraph numbers or using tracked changes. 